\title{
Need Analysis to Develop Anti-Corruption Behavior of Early Childhood Through Parenting Education Model
}

\section{Uswatun Hasanah and Tarma}

Family Welfare Vocational Education, State University of Jakarta, Jakarta, Indonesia

\section{Abstract}

The aim of this research and development is to develop a parenting education model to improve the parenting of anti-corruption character in early childhood. The result of need analysis identifies existing condition about anti-corruptive parenting, corrupt or anti-corruption character in early childhood, parenting education model needed by parent and anti-corruption learning media. The survey results to 55 parents of kindergarten students, obtained a description of the parenting education model needed by parents. The result of need analysis is known that the parents do not yet know the character of anticorruption, aren't yet aware of the anti-corruptive behavior performed by the child, has not been able to apply the method of parenting to

Received: 11 January 2019 Accepted: 14 February 2019 Published: 25 March 2019

Publishing services provided by Knowledge E

(c) Uswatun Hasanah and Tarma. This article is distributed under the terms of the Creative Commons Attribution License, which permits unrestricted use and redistribution provided that the original author and source are credited.

Selection and Peer-review under the responsibility of the $3 \mathrm{rd}$ ICTVET 2018 Conference Committee. develop anticorruption character of early childhood. All parents do not know all the nine anti-corruption characters. Similarly, about the characters, most of the parents do not understand the character formation process of children. Moreover, the character education method is not understood, let alone be practiced optimally. Methods of character education in families such as value-added, value analysis, value clarification, learning to do, storytelling, conversations, habituation, rewards, and punishments are not fully understood and practiced by parents at home. Based on needs analysis findings, it is necessary a model of parenting education to develop anti-corruption behavior on early childhood. Based on the characteristics of parents, the parenting education model developed should be simple, applicable, easy to understand and apply the andragogic approach for parents with average education level of senior high school or equivalent.

Keywords: character education, parenting education, anti-corruption behavior

\section{Introduction}

Corruption is a serious problem that occurs in Indonesia. Corruption has a devastating effect widely. The impact of corruption can be proven by high unemployment rate, low education level, high dropout rate, poor quality of public health, decrease the state's income, increase the crime, decrease the purchasing power and bad quality of industrial sector [1]. 
Cases of corruption that occurred in Indonesia is in a state of concern. In 2013, Transparency International has released the Corruption Perception Index score (IPK) that Indonesia has scored 3.2 of a total of 10 points which means Indonesia as a country with high corruption level [2]. In 2014, the Corruption Perception Index has placing Indonesia as a country ranked 107th out of 174 countries [3]. Within the national scope, the number of public complaints about corruption has increased over the last five years (KPK's Report 2010-2014). The prosecution of corruption cases in Indonesia has increased. At the end of 2014, KPK has enforced 1,441 cases, covering inquiry 360 cases, investigation of 397 cases, prosecution of 313 cases, execution of 118 cases, and incracht 183 cases.

Although forms of corruption prevention have been done, the facts of corruption and corrupt behavior is still common in everyday life. The implementation of honesty canteen in many schools also failed [4] and also cheating behavior is still common in schools. Therefore, it needs new diversification and breakthrough in preventing this extraordinary crime.

Corruption are manifestations of weak moral reasoning. It is the essence of the stage of human moral development [5]. Correspondingly, corruption also shows weak character education, which includes moral thinking, moral feeling and moral action [6]. Then, the prevention of corruption in character education perspective gave birth to the concept of character education of anticorruption. There are nine values of anti-corruption character, that is honest, discipline, responsibility, hard work, simple, independent, fair, courageous and caring [7]. The nine values of these characters need to be implanted of the early childhood.

Family is the most important environment to determine the future of the child, as well as the character of a good child starting from the family [8]. Similarly, anticorruption character education should start from the family. Parents can grow the value of anticorruption, develop anti-corruption habits in the family. Character created as the result by imitating the way of thinking and deeds intentionally or unintentionally practiced from their parents [9]. Parents should apply anti-corruption parenting that can be developed a model in parenting education. They were integrated in school or done separately, has not touched the development of anti-corruption character. Rather more emphasis on the development of children in general or specific on the development of potential (interest and talent) of children. The purpose of this study is to know the needs analysis in developing anti- corruption behavior in early childhood through parenting education model. 
Parenting education is a program, supportive service and resources provided to older individuals and caregivers designed to assist them or to increase their capacity and confidence in child health care [10]. Parenting education as a parent intervention or any attempt to influence some changes regarding parental understanding or changes in the quality of interaction between parent and child, with the primary goal of optimizing child development [11]. Parenting education as an educational effort that helps improve or facilitate the behavior of parents who have an effect on positive development in their children [12]. Based on these opinions, parenting education is defined as a program aimed at increasing the knowledge and skills of parents to develop anti-corruption character in early childhood. Etymologically, parenting is a compound word derived from pattern and upbringing. Pattern means "model, image or piece for example". And defined as "system, or way of work". While foster means "keeping, nurturing and educating children". So parenting is the way that parent or educator takes in guarding, caring, educating and directing to be a good person [13]. In terminology, parenting is the attitude of parents in dealing with their children, this attitude can be seen from various aspects, among others from the way parents or educators give rules to children how to give gifts and punishment, the way parents show authority and the way the parent gives attention or responses to the child's wishes [14]. Parenting defined as a common pattern that parents use in caring for their children [15]. Parenting is a complex activity that involves many specific behaviors that work individually and together to influence the child [16]. Based on the above opinion can be concluded that parenting is the mindset, attitude patterns and behavior patterns of parents in interacting with their children in order to develop the potential possessed by the child.

Parenting between one parent and other parents are very diverse. Nonetheless, parenting experts simplify parenting patterns into some types of parenting. Parenting divides into four types, namely democratic parenting, authoritarian, permissive and neglected parenting. Democratic parenting is a parenting pattern that prioritizes the interests of the child, but does not hesitate to control them. Parents with this foster policemen are rational, always underlying their actions on rationale or thoughts. This type of parent is also realistic about the child's abilities, does not expect excessive beyond the ability of the child, gives freedom to choose and supports it with a warm approach. Authoritarian parenting tends to set an absolute standard that must be obeyed, usually accompanied by threats. Authoritarian parenting tend to force, rule, punish if children do not want to do what is said by parents. Permissive parenting patterns provide very loose oversight, allowing their child to do something without adequate supervision. They tend not to admonish or warn their children when in danger, 
and very little guidance is given by parents. Parenting patterns of neglect generally provide a very minimal time and cost to their children. Their time is widely used for their personal needs, such as work.

Anticorruption character education should be conducted in accordance with a child's moral development stage. Moral development is a measure of the height of one's moral morals where moral reasoning determines [18]. Some scholars describe the moral stages differently. Piaget aligns between moral development and cognitive development, because with the development of moral reasoning there is a cognitive change in one's ability to identify moral issues that in their own way attempt to determine moral behavior [19]. Moral development divided in three stages: (1) pre-conventional stage, (2) convectional stage, and post-conventional stage Then the theory of capital development is developed Again by Carol Gilligan Carol (Papalia, et al., 2008: 568) who divides moral development into three phases, (1) pre-conventional, i.e. one is self-reliant, what matters is fulfilling all his own needs. Seen as actions that benefit themselves, (2) conventional, someone sees the needs of others as self-need. Doing good, meaningful, responsible and right action is a self-sacrifice for the benefit of others; And post-Conventional, a person gives a balanced attention between self-interest and the purpose of perpetuating an existing relationship. At each stage there are a number of efforts to optimize the child's morality.

Anti-corruption comes from "anti" and "corruption". "Anti" comes from the Greek -Anth "which means opposite, against, in exchange, instead, representing, rivaling, simulating which means to cross, fight, in exchange, instead, represent/describe, rival, simulate. Etymologically, "corruption" comes from the Latin-corruptio "or" corruptus "and in the older Latin" corrumpere ", which is then adopted in the Indonesian language of corruption [20]. Anti-corruption characterization in children starts from the family environment. Families should be able to support and encourage children to reject all forms of corruption. Some things family can do and observe to be able to instill an anticorruption character in children, namely: (1) respect for honesty in life; (2) the application of religious values in the immediate environment, including in worship activities; (3) providing selfless assistance and self-awareness; (4) dare to account for his behavior; (4) have a high commitment including compliance with regulations; and (5) dare to say the truthful and honest. The aim of this study was to develop an anti-corruption parenting model in families of families. Until now, there has been no anti-corruption education model from the family care approach. For that reason, this research is important to do. 


\section{Research Methods}

Research method used in this research is survey method. Aspects measured in this study include: (1) parental knowledge about anticorruption care; (2) child's anti-corruption behavior; (3) needs analysis of parenting education model to improve anti-corruption parenting; And (4) needs analysis of learning media to support anti-corruption parenting in the family. Data collection instruments using questionnaires. Research respondents are 57 parents of students at As-Salam kindergarten, Cikaum Sub-District, Subang District, West Java Province. Calculation and data analysis using descriptive statistics.

\section{Results}

\subsection{Respondent profile}

In this study our respondent were 55 parents of RA Assalam Class A consist of 69\% women $(n=38)$ and $31 \%$ male $(n=17)$. Based on age, most of the respondents were young families with age range 25-32 years as many as 26 people (47\%). In addition, it is known that most of the parents' families come from mixed ethnic groups as many as 30 people (55\%), and families from marriage monoculture of Sunda as many as 25 people (45\%). Then most parents are educated high school/equivalent, were as many as 22 people (40\%). While the rest are graduates of junior high school (14 people or $25 \%), 18 \%$ of elementary school graduates (10 people), $7 \%$ graduate diploma (person), $7 \%$ graduate (4), and $2 \%$ other. In the job dimension, most respondents are housewives (19 people or 35\%). The second largest is as entrepreneurs as many as 12 people (22\%). In addition, most parents learn by watching educational TV/CD/DVD (40\%) and the rest are spread on internet access habits (15\%), listening to lectures (15\%), reading books (5\%) and all combinations answer are $25 \%$.

Based on the results of the survey to 55 parents of grade A kindergarten students, it is known information about the parent's profile as follows: (1) most parents are aged 25-35 years old, (2) majority of parent were graduated from senior high school, (2) based on cultural background, majority of parent are Sundanese (3) by type of work, most of mothers work as housewives, while fathers work as farmers, private employees, government employee and entrepreneurs, and (4) most parents are not actively learning how to educate their in the right way. 


\subsection{Corruptive behavior}

The description of the anticorruption character indicated by the child is based on information from the parents as follows: (1) the honest character reaches the $32.75 \%$ of the ideal, (2) the caring character reaches $51.25 \%$ of the ideal, (3) the autonomy character reaches the $51 \%$ of the ideal, (4) the discipline character reaches $54 \%$ of the ideal score; (5) the character of responsibility has reached $70 \%$, (6) the character of hard work has reached $52.75 \%$, (7) the humility character has reached $36 \%$, (8) the courage character reaches only $54.75 \%$, and (9) fairness character reaches $48.25 \%$.

Based on the description of the anti-corruption behavior profile described above, it is known that anticorruption care is required by parents at home. So that someday child will become personal internalize anti-corruptive character. Therefore, it is very relevant to develop parenting education model to develop knowledge and skill of parents to educate anti-corruption character for their children.

\subsection{Anti-corruption parenting}

Based on the graph, it is known that the pattern of anti-corruption parenting characteristic done by parents in general has reached $81.72 \%$. But the figure is not in line with the anticorruption character shown by the students. This means that the parent character pattern performed by the parent has not been effective in growing the anticorruption character in the child. In the graph above it is also known that the pattern of weak anticorruption character of the most done by parents is about parenting to build up the honesty character in children who only reached $72.75 \%$ of the ideal. This fact is also consistent with the lowest character value of its internalization by the child that is an honest character

\subsection{Need analysis of model}

Based on the survey results, some of the results are known. Most parents pay attention to the liaison book of children written by teachers at school (84\%). Therefore, the model can be made based on data analysis and facts that can be directly observed by parents. Parents mostly use the book as a source of learning for children (42\%). Therefore, the book is a form of model that can be an option for parents and children. Most parents provide books as a source of learning for children at home (30\%). This confirms that the book is a reliable medium in modeling. Parents' knowledge of moral 
development as well as advantages and disadvantages in children is the domain that gets the most attention (83\%). These results can explain that parents are very concerned about moral development, talent and lack of children from an early age. In this domain, all parents agree to counsel together and accompany the child at the time of study. They also have a willingness to make plans to develop a child's character (98\%). But the next result shows that parents tend to prefer to accompany the child while learning (82\%) than when the child is playing (70\%). Then from $100 \%$ of parents, $34 \%$ of them stated that parents have spare time that can be used to interact with children, while the rest of $66 \%$ have less free time for it. Therefore, the learning model will be more directed to the development of children's learning that can adjust the ownership of the average spare time parents at home. Most of these domains reply that $49 \%$ parents choose "do" activities as their learning modalities. This shows that parents prefer learning models that are learning by doing and do not contain theoretical. When asked related knowledge 9 anti-corruption values, 65\% of parents answered not yet know. Furthermore, $36 \%$ of parents said they did not know that the corrective behavior can occur in children aged 0 s.d. 6 years. However, these results contrast when they state that knowing how to teach children about anticorruption behavior (47\%) and $49 \%$ of them have the ability to teach anti-corruptive behavior well. The next result is also in line with the willingness of parents who are high in educating children at home (42\%). Then this survey also tested the knowledge of parents against corrupt behavior. The result was 55\% answered incorrectly that corruption was only done by state organizers, $51 \%$ answered correctly that corrupt behavior was committed by state officials, $65 \%$ answered correctly that early childhood did not engage in corrupt behavior, 55\% answered correctly that children learned corrupt behavior from their parents, 65\% answered correctly that the child learned the corrupt behavior of his friend and 69\% answered correctly that the child's corrupt behavior is caused by the way parents take care of them. So from the above results can be concluded that the learning model will be made based on general cases that are practical for parents. From the results of several questions related to the knowledge material of anti-corruptive parenting, parents also stated the answer as follows: $45 \%$ of parents answered less know about parenting to prevent corrupt behavior, 38\% parents do not know how to teach anti-corruptive behavior in the family, and $40 \%$ of parents answered less knows about the media that can be used to teach children anti-corruptive behavior. However, 38\% of parents said a lot of know related to parents' knowledge about assessing anti-corruptive behavior in children at home. Therefore, in this domain generate the proposed needs of the 
learning model more emphasis on practical steps and media that is easy to use by parents in teaching anti-corruptive behavior in children.

The survey results to 55 parents of kindergarten students $A$, obtained a description of the parenting education model needed by parents. All parents do not know exactly nine anti-corruption characters. Similarly, about the characters, most of the parents has not understand the character formation process of children. Moreover, about the character education method is not understood, let alone be practiced optimally. Methods of character education in families such as value-added, value analysis, value clarification, learning to do, storytelling, conversations, habituation, rewards and punishments are not fully understood and practiced by parents at home.

Based on the characteristics of parents, the parenting education model developed should be simple, applicable, easy to understand and apply the andragogic approach for parents with average education level of senior high school or equivalent. Because most parents come from Sunda tribe, the context must also be taken into consideration in model development. Based on the level of participation/interaction of parents to the school, it is known that the participation is still relatively minimal. Nevertheless, basically parents are still potential to be developed/enhanced again participation/interaction or involvement in school activities. Aatas basic it is still visible to be implemented parenting education in the school. Under home conditions, almost all parents do not have adequate learning facilities at home. Books, educational game tools, interactive $\mathrm{CDs}$, learning movies are still minimal owned by parents. Internet access for education is also still minimum. Generally parents access the internet through gadgets for social media. Educational ability in the family owned by parents is still low. Similarly, the time management ability to provide positive parenting is weak. Based on the learning modalities, most parents learn more through visual and audiovisual media.

To support the implementation of the model of parenting as well as the application of the results of parenting education at home will require learning media in accordance with the characteristics of parents and children. Based on the survey needs analysis, it is known that the required learning media is visual and audio-visual media.

\subsection{Need analysis of media}

Based on the need analysis of media, some of the results are known. $79 \%$ of the results state that parents say that children are more happy when parents tell stories. The most favorite story of the fairy tale by children is a fictional story (38\%). Then from the results is also known that more than $80 \%$ of children liked the story of animals (fable). $74 \%$ 
of parents stated that children prefer reading books rather than other visual media. Meanwhile, 35\% of children love picture stories when reading books. When asked again, it turns out about $65 \%$ of children prefer animated characters (cartoons) in their picture book. Most parents stated that their child prefers educational games (such as cards, pictures) (74\%). Meanwhile $89 \%$ of children love cartoons. This is supported by the results of $95 \%$ of parents surveyed have television and DVD Player in their homes. However, subsequent results state that most parents (69\%) have few educative films or child education films. Most of the parents we surveyed did not have an internet network at home (75\%). However, they can access the internet via modem or mobile (76\%). It is also supported by the statement that children rarely access the internet via laptop or computer (49\%). Then the children also sometimes access the internet via mobile phone or tablet (31\%). Parents also assure that their children do not access online games (40\%). In addition, the same thing happens to access movies watching on YouTube, websites and social media in children. Therefore, media made with internet based should be in the form of applications that can be accessed on mobile phones.

\section{Conclusion}

The needs analysis identified the existing condition of the anticorruption character pattern as well as the need for parenting education. Parents does not know the value of anti-corruption character, does not know the pattern of foster anti-corruption, does not knowing and yet skilled in implementing method of anticorruption character building.

\section{References}

[1] Indonesia Corruption Eradication Commission. (2014). Annual Report 2014. Jakarta: Indonesia Corruption Eradication Commission.

[2] Wijaya, D. (2014). Anticorruption Education for School and University. Jakarta: Indeks.

[3] Transparency International. (2014). Corruption Perception Index 2014. Germany: EYGM Limited.

[4] ICW. (2010). Indonesia Corruption Eradication Commission About Bankruptcy of Honesty Canteen; Signs of Early Corruption. Online. Available on http://www. antikorupsi.org/id/content/kpk-soal-bankrutnya-kantin-kejujuran-jadipertandakorupsi-dini. [accessed January 19th, 2016].

[5] Kohlberg, L. (1981). The philosophy of moral development. San Francisco: Harper \& Row. 
[6] Lickona, Thomas. (1991). Educating for Character: How Our School Can Teach Respect and Responsibility. New York: Bantam books.

[7] Justiana, S., et al. (2014). Education and Anticorruption Culture Textbook. Jakarta: Center of Education and Training of Medicine Workers.

[8] Megawangi, R. (2009). Character Education: The Right Solution to Building a Nation. Bogor: Indonesia Heritage Foundation.

[9] McLoyd VC. Socioeconomic disadvantage and child development. American Psychologist. 1998;53(2):185-204.

[10] Carter, N. (1996). See how we grow: A report on the status of parenting education in the U.S. Archived and available upon request at info@pewtrusts.org

[11] Cowan, P. A., Powell, D., \& Cowan, C. P. (1998). Parenting interventions: A family systems perspective. In W. Damon (Ed.) \& I. Sigel \& K. A. Renninger (Vol. Eds.), Handbook of child psychology: Vol.4. Child psychology in practice (5th ed., pp. 3-72). New York: Wiley.

[12] Smith, C., Perou, R., \& Lesesne, C. (2002). Parent education. In M. H. Bornstein (Ed.), Handbook of Parenting: Vol. 4. Social conditions and applied parenting (2nd ed., pp. 389-410). Mahwah, NJ: Erlbaum.

[13] Subarjono, T. et al. (without year). Blueprint of the Communication Strategy for Long-Term Anti-Corruption Education and Culture (2012-2025). Jakarta: Republic of Indonesia Ministry of Communication and Information.

[14] Thoha, C. (1996). Kapita Selekta Islamic Education. Yogyakarta: Pustaka Pelajar.

[15] Ormrod, Jeanne Ellis. 2008. Educational Psychology Helps Students Grow and Grow Sixth Edition Volume 2. Jakarta: Erlangga.

[16] Ormrod, Jeanne Ellis. 2008. Educational Psychology Helps Students Grow and Grow Sixth Edition Volume 2. Jakarta: Erlangga.

[17] Baumrind, D. (1967). Child care practices anteceding three patterns of preschool behaviour. General Psychology Monograph, 75, 43-88.

[18] Santrock, J. W. (2011). Life-Span Development (13th Edition). New York: McGraw Hill.

[19] Santrock, J.W. (2009). Educational Psychology. Jakarta: Salemba Humanika.

[20] Handoyo, E. (2009). Anticorruption Education. Semarang: Widya Karya. 